\title{
A Direct Vocabulary Teaching Model Based on Three Paradigms of Connection: An Action Research
}

\author{
Laurie Xiang Lu \\ Nelson Marlborough Institute of Technology, Nelson, New Zealand
}

\begin{abstract}
This paper discusses a research project on vocabulary teaching and learning carried out at Nelson Marlborough Institute of Technology (NMIT) in 2012. The project consists mainly of two parts: 1. Conducting a preliminary study on NMIT English for speakers of other languages (ESOL) students' vocabulary learning activities and/or strategies; and 2. Trialing out an integrated direct approach to vocabulary teaching and learning, namely, the three-paradigm connection model, adopted in response to the identified learning strategies that students show preferences to. This deliberate teaching and learning model comprises of two key inter-related and complementary principles: 1. A packaged delivery including two paradigms of connection in direct vocabulary instruction; and 2. Some engaging follow-up activities initiated by tutors to support and sustain further individual learning. The integrated approaches of three paradigms - contextualizing a lexical item, noticing its predictable patterns, and deliberate restudy or generative reuse of them in communication — not only help students with the cognitive and productive mastery of English vocabulary, but also endorse a sound guiding model that enables learners to take more efficient control of their vocabulary learning in a wide range of individual learning contexts.
\end{abstract}

Keywords: direct/indirect teaching strategies, horizontal/vertical association, follow-up activities, blended learning

\section{Introduction}

This paper is to review the findings of an English vocabulary learning and teaching research project carried out at Nelson Marlborough Institute of Technology (NMIT) from 2012 to 2013. The project consists mainly of three parts: (a) a preliminary study on NMIT English for speakers of other languages (ESOL) students' vocabulary learning activities and/or strategies; (b) some direct vocabulary teaching practices organised in response to the identified learning strategies that students show preferences to; and (c) some further investigations into learners' online vocabulary learning behaviour and their feedback about the new blended learning practices. Data related to learning strategies were garnered via the mode of online questionnaire survey completed by 43 students (see Appendix A). Two paper-and-pen vocabulary tests designed to assess students' vocabulary knowledge involving form and meaning recognition, form and meaning recall, and reuse were conducted to gauge the learning results (see Appendix B) of two different approaches to vocabulary instruction and learning. Student feedback focusing on ensuing Web-based learning was also sought in the subsequent sessions via interviews and online questionnaire (see Appendix C). The main purpose of the research is to attempt an identification of some simple yet practical teaching and self-learning guiding strategies that either seem to better suit students' learning styles or are believed to exert more positive influences on their

Laurie Xiang Lu, M.A., senior academic staff member, Nelson Marlborough Institute of Technology. 
learning behaviour and learning efficiency.

\section{Learning Strategies in Action: Key Findings and Implications}

The online vocabulary learning strategy questionnaire made up of 25 multiple choice statements intend to probe into five main areas of concern: (a) noticing the new words; (b) meaning and usage checking; (c) recording new words; (d) consolidation; and (e) creative use.

Firstly, about $80 \%$ of the students surveyed refer to reading as the main source of new words that they usually notice and learn, and they mainly rely on themselves to decide what words to learn from the texts. The percentage in this category (55.81\%) is higher than that of all other categories by nearly 12 points. About $56 \%$ of the students tend to check the dictionary for meaning while the other $44 \%$ try to guess the meaning first. And when they guess, the majority of them try to analyse word structure $(79.07 \%)$ and relate to collocation $(74.42 \%)$ and semantically related words $(67.44 \%)$.

One of the key messages that can be possibly picked up here is that reading, as a main source of lexical input for students, provides a vital channel for students to learn and teachers to teach new words. This being the case, a teacher will have to be upfront about the options of teaching new words in a more direct or indirect manner and also the situations and implications of teaching new words either before, during, or after reading.

Although $74.42 \%$ of the students rely on a dictionary for meaning checking and $65.12 \%$ use an electronic dictionary, the majority do agree that they find it works better for them to check with a teacher both for the meaning (53.49\%) and usage (76.74\%) in particular. Eighteen out of 43 students $(41.86 \%)$ acknowledge the importance of knowing the meaning as well as the word class and its collocation with other words when they want to learn how to use a word.

Evidently, students need teachers' help. The reality, however, is that students do not often ask and teachers do not always interfere or help, and an important question related to this fact is whether a teacher should take the initiative and play a more active role in students' vocabulary acquisition.

In terms of recording new words, over $90 \%$ students acknowledge using either a special vocabulary notebook $(65.12 \%)$, or a teacher-made vocabulary worksheet/workbook $(18.60 \%)$, or an electronic device (6.98\%). Almost 70\% record the meaning in their first language. Recording the grammatical category (part of speech) and making notes of grammatical pattern of new words account for $86.05 \%$ and $72.09 \%$ respectively.

What is clear from the above observation is that there is a certain degree of student autonomy and there is a general awareness of the need to record the new words for relearning. And this leads very naturally to the question of what should be recorded for a lexical target. Is it the part of speech, meaning, pronunciation, and/or something else?

Most students acknowledge reviewing new words. Their preferred way of revising new words is repeating the words either silently $(41.86 \%)$ or aloud $(39.53 \%)$, and they seek ways to re-encounter new words either through reading and listening extensively $(41.86 \%)$ or using them in speaking and writing $(27.91 \%)$.

How extensive should reading and listening activities be in order to ensure that the students will reencounter a specific set of target words? Should it be a pure process of "hit and hope"? More specifically, how good the chances really are for the students to meet the target words again in a time-framed course learning context? Can the teachers help? If yes, how?

When creative use of those newly learnt words is concerned, over half of the students (62.79\%) reported that they either sometimes or seldom have a chance to use the new words in the class. Although nearly a third 
of the students regard reusing new words in speaking or writing as the most effective way to master new words, the majority (nearly 70\%) refer to vocabulary exercise and reading or listening as the best way to learn.

According to the students, learning focusing on vocabulary and receptive skills helps better. It shows in a way how important a role repetition plays in vocabulary learning. A pertinent question worth pondering upon here is about the necessity of providing vocabulary-focused practice regularly or more regularly. If teachers' provision or help is deemed necessary, how can it be done in a more practical and constructive way?

Table 1 is a brief summary of the key findings accompanied by some tentative explanations and related questions for us to ponder upon.

Table 1

Students' Vocabulary Learning: Styles and Implications

\begin{tabular}{|c|c|c|}
\hline Students' learning styles & Possible implications/reality & Related questions \\
\hline $\begin{array}{l}\text { Reading as the main source of lexical } \\
\text { input }\end{array}$ & $\begin{array}{l}\text { A vital channel for students to learn and } \\
\text { teachers to teach new words. }\end{array}$ & $\begin{array}{l}\text { Indirect or direct teaching of new words } \\
\text { before/while/after reading? }\end{array}$ \\
\hline Being self-decisive in word selection & \multirow{2}{*}{$\begin{array}{l}\text { Student autonomy. } \\
\text { Students need teachers' help and teachers } \\
\text { do not always interfere/help (a lot of } \\
\text { indirect learning). }\end{array}$} & \multirow[b]{2}{*}{$\begin{array}{l}\text { More active teacher's role in students' } \\
\text { vocabulary acquisition? }\end{array}$} \\
\hline $\begin{array}{l}\text { Checking with a teacher yields a better } \\
\text { understanding of meaning and usage in } \\
\text { particular }\end{array}$ & & \\
\hline Using vocabulary notebook to record & $\begin{array}{l}\text { Reviewing is important. } \\
\text { Student autonomy. }\end{array}$ & What should be recorded? \\
\hline $\begin{array}{l}\text { Reading and listening extensively to meet } \\
\text { the new words again }\end{array}$ & $\begin{array}{l}\text { Indirect learning is helpful and useful. } \\
\text { Hit and hope. }\end{array}$ & $\begin{array}{l}\text { Are the chances good to meet the target } \\
\text { words again? } \\
\text { Can the teachers help? How? }\end{array}$ \\
\hline $\begin{array}{l}\text { The best way to learn: vocabulary exercise } \\
\text { and reading or listening activities }\end{array}$ & $\begin{array}{l}\text { Learning focused on vocabulary and } \\
\text { receptive skills helps more. } \\
\text { Repetition plays a big part. }\end{array}$ & $\begin{array}{l}\text { More regular vocabulary-focused } \\
\text { practice? How? }\end{array}$ \\
\hline
\end{tabular}

\section{Discussions: Questions and Answers}

In answer to these questions generated from the above observations and implication interpretations, an integrated direct approach is proposed to be an effective and easy-to-use model. This deliberate teaching and learning model should comprise of two key inter-related and complementary principles: 1 . A packaged delivery featured by two paradigms of connection in direct vocabulary instruction; and 2. A couple of engaging follow-up activities initiated by tutors to support and sustain further individual learning.

Discussions on the value of direct vocabulary teaching will be spared here as the research literature is already inundated with positive findings about the benefits of teaching students vocabulary directly. This survey has also confirmed that students welcome teachers' help. What this research interests itself in is some of the practicalities concerned with teaching vocabulary directly to the ESOL students.

The first practicality is a so-called packaged delivery principle, which refers to adopting a structured integrated approach both for teachers to teach and students to learn. The key part of this model is made up of two paradigms of connection (see Figure 1) that can be put in a figurative way: left to right connection (horizontal) and up and down connection (vertical).

Left to right connection refers to presenting words by showing the chunking of meaningful units, which manifest themselves either in such mini contexts as idioms (e.g., pull one's leg), set phrases including phrasal verbs (e.g., put up with), formulated expressions (e.g., What is more), collocations (e.g., do the washing up), independent syntactic structures like sentences (e.g., What is up), and so on. Learners are better off by learning such chunked expressions like "Antarctic Continent", "Arctic Ocean", "strip dancing", and "Stars and Stripes" 
than focusing on learning individual words like "Antarctic", "Arctic", "strip", and "stripe" respectively. "Chunked expressions enable learners to reduce cognitive effort, to save processing time and to have language available for immediate use" (Pawley \& Syder, 1983). It makes good sense for a teacher to find and present to the students those meaningful and most yielding connections. They are important to the "appropriate interpretation and productive use of vocabulary" (Pawley \& Syder, 1983).

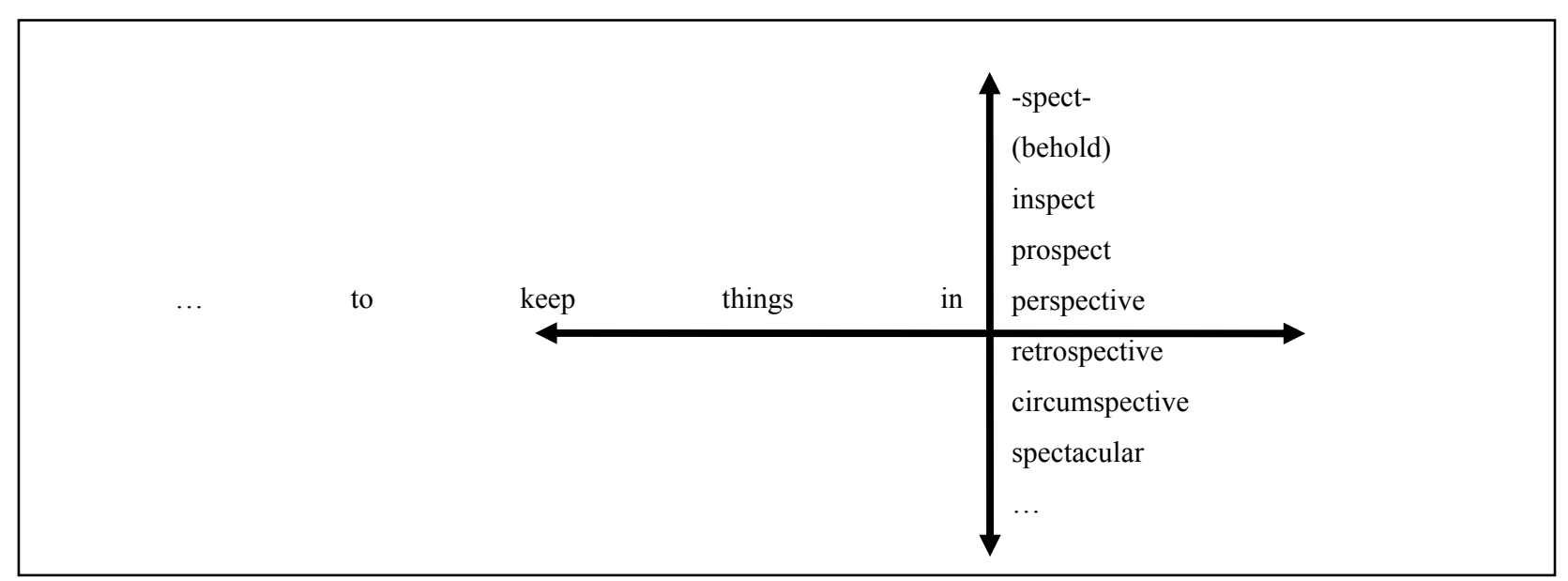

Figure 1. The two-paradigm connections.

Up and down connection is to show a word in relation to its word family comprised of a headword, its infected forms and closely related derived forms. Studying systematically used affixes can "greatly reduce the learning burden of derived words containing known base forms" (Nation, 2009).

These connections should be incorporated into the teaching and learning process of new words in which many other intrinsic connections also exist, such as that between graphemes and phonemes or form and meaning. "Presenting words in related fashion facilitates the learning of second language vocabulary" (Papathanasiou, 2009).

The two lines of connections do not have to bear the same weight in every delivery. Their role is case sensitive and varies accordingly. Any attempts to approach a word along these two dimensions should be encouraged. And the same principle should be promoted among the students, especially in word recording to better guide their own learning of new words. It is believed that efficient learners are those who adopt a structured approach to vocabulary learning by keeping systematic records of their vocabulary learning by using notebooks or lists and doing reviews (Nation, 2001).

The second practical principle - facilitating engaging follow-up activities to support and sustain further learning — on the other hand, stipulates that teachers should take the initiative and provide the second and third learning opportunities for the students. This brings in the third paradigm of connection, which simply means bridging one vocabulary learning experience with some other learning experiences that provide the students with new chances to get back to the target words. It indicates the need for the teachers to provide on-going learning tasks, be it commercially produced or self-made. It can be as dumb as vocabulary reviewing activities or as smart as linked skills activities as proposed by Nation (2008). The former tends to be more mechanical, boring, and beneficial to receptive mastery of vocabulary while the latter can be more engaging and focusing on the productive mastery. Preparing linked skills activities demand more careful planning and may not be really easy to come by and well associated (see Table 2). Anyway, "Repetition of new word forms is a useful strategy, 
and sustained follow-up of initial learning is essential for long-term memory" (Nation, 2001).

Table 2

Features of Two kinds of Three-Paradigm Association

\begin{tabular}{|l|l|}
\hline Conventional reviewing activities & Linked skills activities \\
\hline More direct and focused; & More engaging; \\
More mechanical and less interesting; & Meaning-focused and thus focusing on productive mastery; \\
Language-focused and thus beneficial mainly to receptive & Need more careful planning; \\
mastery. & Not easy to come by and time-consuming. \\
\hline
\end{tabular}

In short, the three paradigms of connection - contextualising a lexical item, revealing its predictable patterns and retrieving it in meaning-focused input (like reading and listening), and deliberate restudy or generative reuse of them in communication — not only help with cognitive mastery, but also the development of fluency - the productive mastery.

\section{Teaching Experiments and Results}

A comparative study on two ways of teaching vocabulary - the definitional model and the new model using integrated connections of three patterns - was conducted to 20 students from two intermediate classes to determine the effectiveness of the proposed model.

The experiment was phased into two stages (see Figure 2), each of which lasted for four weeks. Both started with a session of direct vocabulary teaching for about half an hour and ended with a vocabulary test four weeks later.

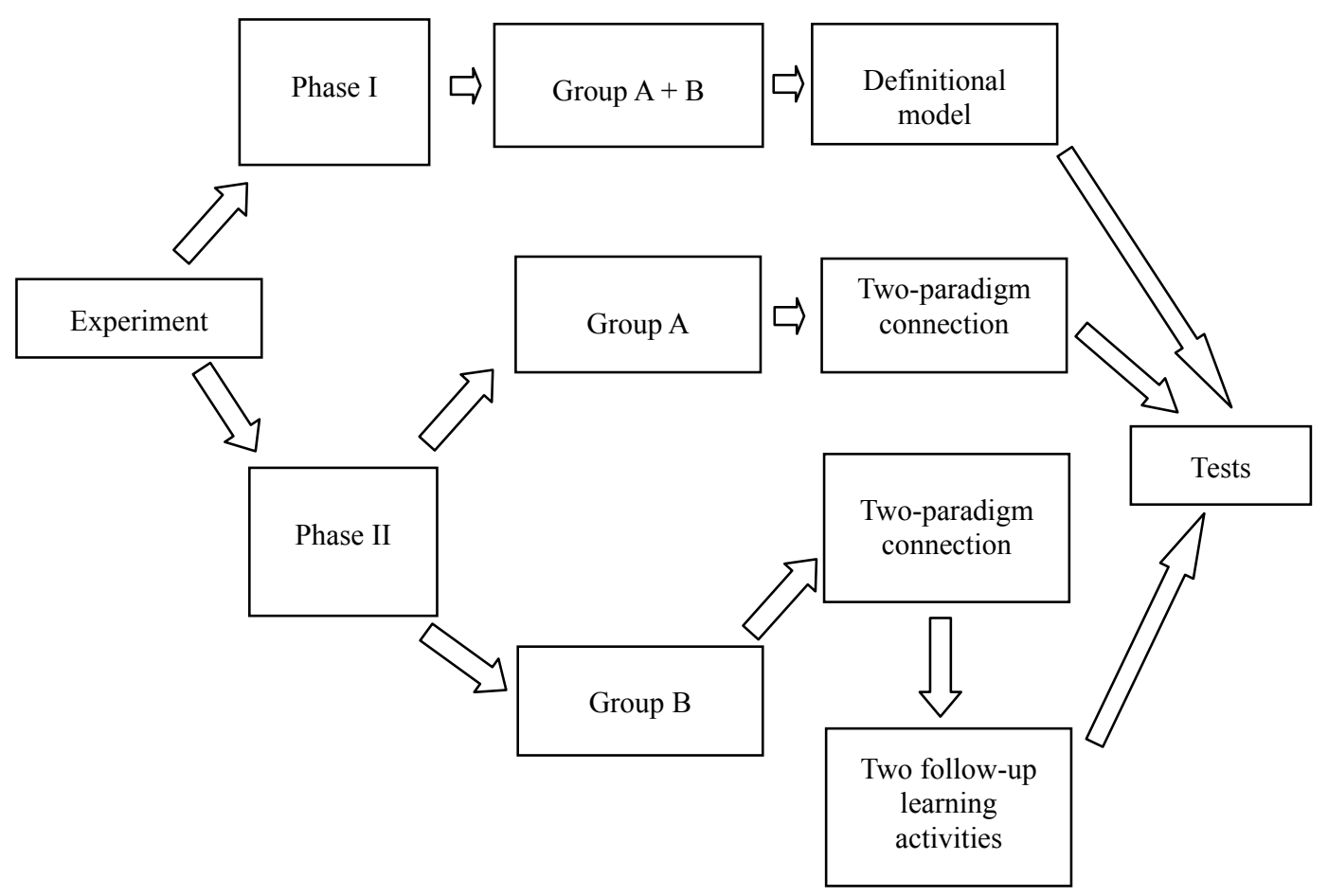

Figure 2. The flow chart of the experiment.

Firstly, 40 uncommon words were picked out from two separate academic reading texts and were then randomly put into two groups. One group of 20 words was first taught in the definitional model to the students. 
With the assistance of a teacher-made vocabulary learning/recording sheet, the teacher taught the students mainly the part of speech and meaning and pronunciation of each word. Twenty minutes later, the students had another 15 minutes to study the words both by themselves and with the teacher. The students took over from here and no further class learning of these words was provided. They, however, were clearly instructed to review the words in their self-study time. Four weeks later, a test designed to measure the students' mastery of these words was administered. The test consists of three parts: 10 multiple choice questions for form identification (spelling), 10 lexical items for students to write definitions in their first language or English (meaning recall/checking), and summary completion by choosing 10 words from the given 15 words (reuse).

In Phase II, the packaged delivery model was conducted by using a new vocabulary learning sheet containing another 20 academic words. Two kinds of connection were applied in the 35-minute direct instruction, which includes 15 minutes of self-study time.

However, the participated students in Phase II experiment were split up and treated in two different ways in regard to the third connection. That is, two kinds of follow-up revision activities were carried out. The first group (Group A) was asked to review from the vocabulary learning/recording sheet just like what they normally do with the new words while the other group (Group B) did a meaning-focused reading comprehension exercise with the teacher in the class one week later. The reading text contains many (not all) of these 20 target words. In addition, this group of students were introduced to an online vocabulary learning class on Quizlet, which is called IELTS2012T3-4. Students were shown how to use this online tool in one of their guided individual learning (GIL) sessions. After this, the reign was handed over to the students. No further help was offered to the students. Another vocabulary test was organised after an interval of four weeks.

According to the test results (see Appendix B), students showed an overall increase of average scores in meaning recall (by almost 46\%) and reuse (by nearly 10\%). The average score for the most passive part-form recognition-however, went down by nearly $12 \%$ due to the $31 \%$ decrease of Group A in this section. This particular group also had a decline of $12.5 \%$ for reuse section. The reasons for these two poor indicators are yet to be determined. At this stage, a sensible presumption is that the students might have lost their concentration a bit near the end of the semester.

Group B, on the other hand, demonstrated a consistent improvement in all the three aspects of vocabulary study. Their average score for form recognition nudged up by $12.5 \%$ and they scored slightly over $18.3 \%$ higher in reuse. What is more, there is a hefty rise of nearly $82 \%$ in meaning recall. Despite all the caution that should be taken when interpreting data generated from such a small-sized research where the interference of many uncontrollable factors has also to be ignored, this $82 \%$ rise is still a strong indication of good vocabulary retention. The improved performance is believed here to have come from nowhere else but the meaningful and engaging follow-up study - reading and online relearning facilitated by the tutor although it cannot be determined at this stage how much the improvement has to do with the other two paradigms of connection. And such a distinct disparity between the group performances in the two phases and the gap between the two groups in Phase II, on the other hand, show convincingly the difference relearning, mainly blended learning, can make to the effective mastery of English vocabulary, especially the cognitive mastery.

It is also noted that the average scores in reuse section are low for both classes. Even Group B, treated with packaged delivery and teacher guided self-learning, scored only 2.5 out of 10 . It provides, however, no substantial evidence to conclude that the integrated model enhances nothing but cognitive mastery of new words. Instead, it seems to have more to do with the fact that completing a summary for an unmodified 
argumentative text is just a bit too hard as it contains not just challenging concepts but also lots of complex sentences and many other less commonly used words. What can be taken from here is perhaps the other and more evident message, i.e., there is a genuine need to widen the scope of the third paradigm association in the future practice by including more relearning activities related to the creative reuse of the learnt words. Linked skills activities can be an answer. And project-based learning under the new New Zealand Certificate in English Language (NZCEL) framework, where students will be able to have multiple opportunities to learn and practise the same set of vocabulary by tackling different types of tasks over the project period may give students and teachers a better opportunity to achieve the effect.

\section{Web-based Vocabulary Learning: Feedback and Discussions}

Further research attempts to collect students' feedback about using free online vocabulary learning tools, which include vocabulary learning classes run on Quizlet, Vocabulary Quizzes, Forum, and Chat Room on NMIT Online (Modular Object-Oriented Dynamic Learning Environment (Moodle)) dedicated specifically to vocabulary learning and some freely available vocabulary learning websites like Spellcity, Lextutor, BN Corpus, etc.. All of these tools are made accessible to students under one roof-the vocabulary learning module in the online (Moodle) course entitled "Academic English S3 2013".

The Web-based/online relearning environment was meant to be made user-friendly, engaging, and effective. Online vocabulary learning courses on Quizlet and Moodle are initiated and facilitated by the teacher. It is the students, however, who run their own race. Students have the freedom to use these online tools for any length of time either in their allocated GIL sessions or in their own disposable time. Apart from the Quizlet classes-IELTS2013 and IELTS2012T3-4, five teacher-led vocabulary relearning sessions happened in GIL sessions. They contain four rounds of forum discussions (with a total of 154 posts) and one round of chat room discussions, where the foci were mainly on sharing newly learnt vocabulary, recounting personal vocabulary learning experience, reflecting on one's own way of vocabulary learning, and exploring better ways to learn new words.

Eighteen weeks later (including two weeks of term break), a questionnaire survey was conducted among a group of 16 students, focusing on two key aspects of information: (a) factual information about students' learning behaviour; and (b) attitudinal information regarding how the students feel about using online learning tools to enhance their vocabulary learning. Subsequent face-to-face interviews were also carried out to seek deeper understanding of the rationale behind students' answers to some of the questions.

Almost $90 \%$ interviewees think that online learning tools are either useful $(43.75 \%)$ or very useful (43.75\%) and nobody thinks otherwise. When asked how online tools have helped them with their vocabulary learning, $43.75 \%$ attribute it to the fact online tools make vocabulary learning easier (in the sense of convenience) and another $31.25 \%$ believe that it is not just easier but also more interesting and effective to learn new words. This may help to explain why around $40 \%$ of the students acknowledge to have spent less time on vocabulary learning since the availability of online tools.

As mentioned, none of the 16 respondents denies the usefulness of online vocabulary learning. In fact, $31.25 \%$ think that online learning is the best way to learn. The majority $(68.75 \%)$, on the other hand, concede that online learning is a good supplementary way to learn. One of the main reasons, as also made clear in the interviews, is that vocabulary is so individual and a good mastery, especially productive mastery, will demand the learner to practise using the new words in different contexts. 
Blended learning seems to help enhance students' autonomy as the survey indicates that nearly $70 \%$ of the students can take the initiative and decide for themselves when to use these online study tools without the need of being asked or monitored. In fact, $18.75 \%$ of the students are found to use new technology only for vocabulary study. Although $12.50 \%$ prefer to hold on mainly to their conventional ways to learn, as many as $87.50 \%$ of the students prefer using online learning tools or Apps on their smartphones or tablets to learn vocabulary while $56.25 \%$ admit using both new technologies and conventional ways to learn.

In the Web-based learning context, around a third of the students prefer to work individually to learn new vocabulary whereas half of the respondents like to work both individually and in cooperation with other students like using forum or chat room. In terms of the most helpful online learning activity, a quarter of the respondents find writing activities, like constructing sentences and writing posts, help them the most in vocabulary learning whereas as many as $56.25 \%$ believe vocabulary exercises and tests, like those automatically generated ones on Quizlet, help them the best with cognitive mastery, which obviously is of prime concern to these students at the initial stage.

Questionnaire and interview results seem to support the claim that online learning facilities provide a much needed and effective way to sustain students' further learning. It engages learners and gives them more control and flexibility. And teachers will find it less a burden to initiate and support online learning than having to design and implement relearning activities in a conventional way. Having said so, it should also be kept in mind that online vocabulary learning activities have not yet provided direct empirical evidence to the productive mastery of vocabulary although the evident cognitive mastery as strongly suggested by experiment results and the positive feedback from the students is surely vital to the development of productive mastery. And online learning classes need constant maintaining and updating to ensure its usability to a new group of learners. Anyway, online learning is not supposed to dominate or replace students' self-guided relearning done in a way which may better suit each individual's unique learning style and needs. A sound Web-based relearning model should serve to facilitate and complement students' independent learning.

\section{Conclusion}

The findings from the investigation seem to put the researcher in a good position to suggest that students' lexical development can be better facilitated and enhanced by teachers' providing direct vocabulary instruction along the two paradigms of connection and offering continued support in students' learning curve. An integrated approach by systematically employing the proposed packaged instruction and support strategies, especially Web-based learning environment, creates a most favourable blended learning environment, which tends to endorse a sound guiding model that enables learners to take more efficient control of their vocabulary learning in a wide range of individual learning contexts as well.

\section{References}

Nation, I. S. P. (2001). Learning vocabulary in another language. Cambridge, U.K.: Cambridge University Press. Nation, I. S. P. (2008). Teaching vocabualry: Strategies and techniques. Boston, M.A.: Heinle Cengage Learning. Papathanasiou, E. (2009). An investigation of two ways of presenting vocabulary. ELT Journal, 63(4), 313-320.

Pawley, A., \& Syder, F. H. (1983). Two puzzles for linguistic theory: Nativelike selection and nativelike fluency. In C. J. Richards, \& R. W. Schmidt (Eds.), Language and communication (pp. 191-225). London, U.K.: Longman.

Schmit, N. (1997). Vocabulary learning strategies. In N. Schmit, \& M. McCarthy (Eds.), Vocabulary, description, acquisition and pedagogy (pp. 199-207). Cambridge, U.K.: Cambridge University Press.

Sonbul, S., \& Schmit, N. (2010). Direct teaching of vocabulary after reading: Is it worth the effort? ELT Journal, 63(3), 253-319. 


\section{Appendix A: Students' Vocabulary Learning Strategies}

Table A

Students' Vocabulary Learning Strategies (Submitted Answers = 43; Questions $=25$ )

1. I learn most of my new words from
(a) Reading;
(b) Listening;
(c) Speaking;
(d) Writing.
$34(79.07 \%)$
0
$7(16.28 \%)$
$2(4.65 \%)$

2. I usually

\begin{tabular}{|l|l} 
(a) Decide for myself what words to learn from the texts; & $24(55.81 \%)$
\end{tabular}

(b) Rely on others (like teachers, friends, or textbooks) to tell me what words to learn.

$19(44.19 \%)$

3. When coming across with a new word, I usually
(a) Guess the meaning;
$19(44.19 \%)$
(b) Look it up in the dictionary;
$24(55.81 \%)$
(c) Skip to ignore.
0

4. When guessing, I usually

(a) Analyse word structure (like prefixes, suffixes, and so on);

(b) Do not analyse word structure.

$34(79.07 \%)$

$9(20.93 \%)$

5. When guessing, I

(a) Relate the word to collocations;

$32(74.42 \%)$

(b) Do not relate the word to collocations.

$11(25.58 \%)$

6. When guessing, I

(a) Relate the words with semantically related words in the text (like tree, wood, timber, forest, etc.); $\quad 29(67.44 \%)$

(b) Do not relate the word with semantically related words.

$14(32.56 \%)$

7. To know the meaning of a new word, I mainly
(a) Use a dictionary;
(b) Ask other people (like a teacher or friend) for explanation.
$32(74.42 \%)$
$11(25.58 \%)$

8. I mainly use
(a) An electronic dictionary;
$28(65.12 \%)$
(b) A paper dictionary.
$15(34.88 \%)$

9. I know the meaning of a word better by
(a) Checking the dictionary;
$20(46.51 \%)$
(b) Checking with a teacher.
$23(53.49 \%)$

10. I know the usage of new word better by
(a) Checking the dictionary;
$10(23.26 \%)$
(b) Checking with a teacher.
$33(76.74 \%)$

11. I learn how to use a new word mainly
(a) By knowing its meaning;
(b) By knowing its word class (part of speech);
$12(27.91 \%)$
(c) By knowing its collocation with other words;
$6(13.95 \%)$
(d) By knowing all of the above.
$7(16.28 \%)$
$18(41.86 \%)$

12. I use to record new words
(a) A vocabulary notebook;
(b) A teacher-made vocabulary worksheet or workbook;
$28(65.12 \%)$
(c) A smart phone or another electronic device
$8(18.60 \%)$
(d) My brain only.
$3(6.98 \%)$
$4(9.30 \%)$

13. When recording, I write down new words and then

(a) Their definitions in my first language (like Arabic or Chinese);

$30(69.77 \%)$

(b) Their definitions in English.

$13(30.23 \%)$ 
(Table A to be continued)

\begin{tabular}{|c|c|}
\hline \multicolumn{2}{|c|}{ 14. I _ the grammatical category (part of speech) of the new words. } \\
\hline (a) Record; & $37(86.05 \%)$ \\
\hline (b) Do not record. & $6(13.95 \%)$ \\
\hline \multicolumn{2}{|c|}{ 15. I__ the grammatical pattern of the new words (e.g., contribute to and not contribute for). } \\
\hline (a) Record; & $31(72.09 \%)$ \\
\hline (b) Do not record. & $12(27.91 \%)$ \\
\hline \multicolumn{2}{|c|}{ 16. I__ the pronunciation of a new word. } \\
\hline (a) Record & $24(55.81 \%)$ \\
\hline (b) Do not record & $19(44.19 \%)$ \\
\hline \multicolumn{2}{|c|}{ 17. I__ a new word and its collocation with other words. } \\
\hline (a) Record; & $32(74.42 \%)$ \\
\hline (b) Do not record. & $11(25.58 \%)$ \\
\hline
\end{tabular}

18. I__ a new word together with other semantically related words (like tree, wood, forest, and so on)
(a) Record;
$27(62.79 \%)$
(b) Do not record.
$16(37.21 \%)$

19. I_ a new word together with the affixes (prefixes and suffixes) that can be attached to the new word.
(a) Record;
(b) Do not record.
$21(48.84 \%)$

20. I review the new words.
(a) Often;
$12(27.91 \%)$
(b) Sometimes;
$27(62.79 \%)$
(c) Seldom;
(d) Never.
$4(9.30 \%)$
0

21. When reviewing new words, I
(a) Repeat the words aloud;
(b) Repeat and spell the words aloud;
(c) Repeat the words silently in my mind;
(d) Write the words several times.
$6(13.95 \%)$
$11(25.58 \%)$
$18(41.86 \%)$
$8(18.60 \%)$

22. I most often

(a) Do exercises which contain the new words;

(b) Do rote-learning by repeating the words aloud repeatedly;

(c) Use as many new words as possible in everyday conversation or writing;

(d) Look for opportunities to meet the new words again by reading a lot, watching movies, using the Internet, listening to the radio, etc..

23. In the class, I__ have a chance to use the newly learnt words.
(a) Often;
$6(37.21 \%)$
(b) Sometimes; $23(53.49 \%)$
(c) Seldom; $4(9.30 \%)$
(d) Never.
0

24. I have the best chance to reuse the newly learnt words in
(a) Vocabulary exercises;
(b) Vocabulary tests;
(c) Communication activities (like speaking or writing).
$11(25.58 \%)$
$7(16.28 \%)$
$25(58.14 \%)$

25. I learn new words the best by

\begin{tabular}{|l|c|}
\hline (a) Doing exercises which contain the new words; & $11(25.58 \%)$ \\
\hline (b) Rote learning (like saying the word aloud repeatedly); & $2(4.65 \%)$ \\
\hline (c) Reusing them in speaking or writing; & $14(32.56 \%)$ \\
\hline (d) Meeting them again in listening or reading; & $12(27.91 \%)$ \\
\hline (e) Testing myself. & $4(9.30 \%)$ \\
\hline
\end{tabular}


Appendix B: Vocabulary Test Results

Table B

Vocabulary Test Results

\begin{tabular}{|c|c|c|c|c|c|c|c|c|}
\hline \multirow{2}{*}{ Group } & \multirow{2}{*}{ No. } & \multirow{2}{*}{ Name } & \multicolumn{2}{|c|}{ Form recognition } & \multicolumn{2}{|c|}{ Meaning recall } & \multicolumn{2}{|c|}{ Reuse } \\
\hline & & & Test 1 & Test 2 & Test 1 & Test 2 & Test 1 & Test 2 \\
\hline \multirow{15}{*}{$\begin{array}{l}\text { Class } 2 \\
\text { (Group B) }\end{array}$} & 1 & Gyanu & 9 & 8 & 0 & 7 & 0 & 1 \\
\hline & 2 & Nir & 9 & 10 & 2 & 12 & 1 & 5 \\
\hline & 3 & Khuri & 9 & 9 & 0 & 4 & 0 & 2 \\
\hline & 4 & Kang & 9 & 10 & 0 & 10 & 0 & 2 \\
\hline & 5 & Azooz & 9 & 10 & 1 & 6 & 1 & 2 \\
\hline & 6 & Nehlaw & 9 & 10 & 1 & 11 & 1 & 6 \\
\hline & 7 & $\mathrm{Ha}$ & 9 & 10 & 2 & 12 & 1 & 0 \\
\hline & 8 & Lily & 10 & 10 & 1 & 11 & 1 & 2 \\
\hline & 9 & Paing $\mathrm{Mu}$ & 2 & 10 & 0 & 10 & 1 & 0 \\
\hline & 10 & Mazen & 8 & 7 & 0 & 7 & 1 & 2 \\
\hline & 11 & Hooi Leng & 9 & 10 & 0 & 10 & 0 & 4 \\
\hline & 12 & Naif (Nathan) & 7 & 10 & 0 & 5 & 1 & 4 \\
\hline & Total & & 99 & 114 & 7 & 105 & 8 & 30 \\
\hline & Aver & & 8.25 & 9.5 & 0.583333 & 8.75 & 0.666667 & 2.5 \\
\hline & \multicolumn{2}{|c|}{ Difference between $\mathrm{T} 1$ and $\mathrm{T} 2$} & \multicolumn{2}{|c|}{1.25} & \multicolumn{2}{|c|}{8.166666667} & \multicolumn{2}{|c|}{1.833333333} \\
\hline \multirow{11}{*}{$\begin{array}{l}\text { Class } \\
\text { (Group A) }\end{array}$} & 1 & Aale & 9 & 7 & 0 & 2 & 0 & 1 \\
\hline & 2 & Amen & 9 & 4 & 0 & 0 & 0 & 0 \\
\hline & 3 & Siang & 9 & 9 & 0 & 2 & 1 & 0 \\
\hline & 4 & Faisal & 7 & 4 & 1 & 0 & 0 & 1 \\
\hline & 5 & Faris & 8 & 2 & 0 & 0 & 2 & 0 \\
\hline & 6 & Dana & 8 & 7 & 1 & 1 & 0 & 1 \\
\hline & 7 & Saeed & 4 & 2 & 1 & 0 & 0 & 0 \\
\hline & 8 & $\mathrm{Li}$ & 7 & 1 & 0 & 0 & 1 & 0 \\
\hline & Total & & 61 & 36 & 3 & 5 & 4 & 3 \\
\hline & Aver & & 7.625 & 4.5 & 0.375 & 0.625 & 0.5 & 0.375 \\
\hline & \multicolumn{2}{|c|}{ Difference between $\mathrm{T} 1$ and $\mathrm{T} 2$} & \multicolumn{2}{|c|}{-3.125} & \multicolumn{2}{|c|}{0.25} & \multicolumn{2}{|c|}{-0.125} \\
\hline \multicolumn{3}{|c|}{ Class difference } & 0.625 & 5 & 0.208333 & 8.125 & 0.166667 & 2.125 \\
\hline \multicolumn{3}{|c|}{ Total for the two classes } & 160 & 150 & 10 & 110 & 12 & 33 \\
\hline \multicolumn{3}{|c|}{ Average for the two classes } & 8 & 6.818182 & 0.454545 & 5 & 0.545455 & 1.5 \\
\hline \multicolumn{3}{|c|}{ Differences of total } & \multicolumn{2}{|c|}{-10} & \multicolumn{2}{|c|}{100} & \multicolumn{2}{|c|}{21} \\
\hline \multicolumn{3}{|c|}{ Differences of average } & \multicolumn{2}{|c|}{-1.181818182} & \multicolumn{2}{|c|}{4.545454545} & \multicolumn{2}{|c|}{0.954545455} \\
\hline
\end{tabular}




\section{Appendix C: Web-based Vocabulary Learning}

Table C

Web-based Vocabulary Learning (Submitted Answers = 16; Questions = 16)

1. Which of the following is true to you?

(a) I use online tools only to study new vocabulary

(b) I use my traditional ways (like vocabulary notebook, etc.) only to study new vocabulary;

$3(18.75 \%)$

(c) I use both online tools and my traditional ways to study new vocabulary.

$4(25.00 \%)$

$9(56.25 \%)$

2. Do you use any vocabulary learning Apps on your smartphones, iPads, tablets, or other electronic devices?
(a) Yes;
(b) No.
$14(87.50 \%)$
$2(12.50 \%)$

3. Which of the following is true to you?

(a) I use new technology such as online learning tools or smartphone Apps more to learn new words; $\quad 10(62.50 \%)$

\begin{tabular}{l|l} 
(b) I use my old ways such as vocabulary notebook more to study new words; & $2(12.50 \%)$
\end{tabular}

$\begin{array}{ll}\text { (c) I use almost as much new technology as old ways to learn vocabulary. } & 4(25.00 \%)\end{array}$

4. Which of the following online learning tool do you use the most for vocabulary learning?

\begin{tabular}{|l|l}
\hline (a) Forum; & $1(6.25 \%)$ \\
\hline (b) Lextutor; & $1(6.25 \%)$ \\
\hline (c) Spellcity; & 0 \\
\hline (d) Visuwords; & 0 \\
\hline (e) Quizlet; & $10(62.50 \%)$ \\
\hline (f) Corpus; & 0 \\
\hline (g) Online dictionaries; & $3(18.75 \%)$ \\
\hline (h) Others. & $1(6.25 \%)$ \\
\hline
\end{tabular}

5. What do you like about your favorite online learning tool?

(a) It offers an interesting, flexible, and effective way to learn new words;

$2(12.50 \%)$

(b) It has a good collection of difficult words;

$5(31.25 \%)$

(c) It is easy to use;

$3(18.75 \%)$

(d) All of the above;

$4(25.00 \%)$

(e) None of the above.

$2(12.50 \%)$

6. I do more online vocabulary study at

\begin{tabular}{|l|l}
\hline (a) School; & $8(50.00 \%)$
\end{tabular}

(b) Home.

$8(50.00 \%)$

7. Which of the following can be true to you?

\begin{tabular}{|l|l}
\hline (a) I use online learning tools only when my teacher asks me to; & $5(31.25 \%)$ \\
\hline
\end{tabular}

(b) I usually take the initiative and decide for myself when to use online learning tools. $\quad 11(68.75 \%)$

8. Which of the following is true to you?

(a) I have spent more time on vocabulary learning ever since the availability of online tools;

(b) I have spent less time on vocabulary learning ever since the availability of online tools;

$6(37.50 \%)$

(c) I have not noticed any change in the amount of time I spend on vocabulary learning.

$7(43.75 \%)$

$3(18.75 \%)$

9. What do you think of online vocabulary learning tools like Quizlet, Corpus, etc.?

\begin{tabular}{|l|l|}
\hline (a) Very helpful; & $7(43.75 \%)$ \\
\hline (b) Helpful; & $7(43.75 \%)$ \\
\hline (c) Not sure; & $2(12.50 \%)$ \\
\hline (d) Not very helpful; & 0 \\
\hline (e) Not helpful at all. & 0 \\
\hline
\end{tabular}

10. How do you think online learning tools have helped you with vocabulary learning?

(a) They make it more interesting to learn new words

$1(6.25 \%)$ 
(Table $\mathrm{C}$ to be continued)

\begin{tabular}{|c|c|}
\hline (b) They make it more effective to learn new words; & $3(18.75 \%)$ \\
\hline (c) They make it easier to learn new words; & $7(43.75 \%)$ \\
\hline (d) All of the above; & $5(31.25 \%)$ \\
\hline (e) None of the above. & 0 \\
\hline \multicolumn{2}{|l|}{ 11. How do you think online learning tools have improved your learning? } \\
\hline (a) I remember the meaning and pronunciation more clearly; & $6(37.50 \%)$ \\
\hline (b) I know better how to use the words; & $7(43.75 \%)$ \\
\hline (c) Both of the above; & $3(18.75 \%)$ \\
\hline (d) None of the above. & 0 \\
\hline \multicolumn{2}{|l|}{ 12. Which do you think works more effectively for you? } \\
\hline (a) Learning new words on your own by using one of the online tools; & $5(31.25 \%)$ \\
\hline (b) Learning new words with others by using one of the online tools; & $3(18.75 \%)$ \\
\hline (c) Both of the above; & $8(50.00 \%)$ \\
\hline (d) None of the above; & 0 \\
\hline \multicolumn{2}{|l|}{ 13. Of all the online learning tools, which one do you find least useful in your study? } \\
\hline (a) Quizlet; & $3(18.75 \%)$ \\
\hline (b) Forum; & $1(6.25 \%)$ \\
\hline (c) Lextutor; & 0 \\
\hline (d) Corpus; & $1(6.25 \%)$ \\
\hline (e) Online dictionaries; & $1(6.25 \%)$ \\
\hline (f) Verb conjugator; & 0 \\
\hline (g) Visuwords; & 0 \\
\hline (h) None of the above. & $10(62.50 \%)$ \\
\hline \multicolumn{2}{|l|}{ 14. What kind of online learning activities do you think help you the most? } \\
\hline (a) Vocabulary exercises or tests; & $9(56.25 \%)$ \\
\hline (b) Reading or listening materials containing the learnt words; & $3(18.75 \%)$ \\
\hline (c) Writing (including writing posts and replies) by using the learnt words; & $4(25.00 \%)$ \\
\hline (d) None of the above. & 0 \\
\hline \multicolumn{2}{|l|}{ 15. What kind of vocabulary do you think online learning help you most with? } \\
\hline (a) Formal words; & $5(31.25 \%)$ \\
\hline (b) Informal words; & $1(6.25 \%)$ \\
\hline (c) Both. & $10(62.50 \%)$ \\
\hline \multicolumn{2}{|l|}{ 16. Which of the following is true to you? } \\
\hline (a) Online learning is the best way to learn vocabulary; & $5(31.25 \%)$ \\
\hline (b) Online learning is a good complementary way to learn vocabulary; & $11(68.75 \%)$ \\
\hline (c) Online learning is not needed for the mastery of vocabulary. & 0 \\
\hline
\end{tabular}

